\title{
A relevância da inserção da propriedade intelectual na pós-graduação brasileira como ferramenta de incentivo à inovação
}

The relevance of inserting intellectual property into Brazilian graduate education as a tool for encouraging innovation

La relevancia de la inserción de la propiedad intelectual en el posgrado brasileño como herramienta para fomentar la innovación

Márcio Martins da Silva Costa, mestre em Engenharia Eletrônica e Computação pelo Instituto Tecnológico de Aeronáutica. Endereço: Praça Barão de Ladário, s/nº . Ed. Alte. Tamandaré - Centro. CEP: 20091-000 - Rio de Janeiro, RJ. E-mail: marcmscosta@yahoo. com.br.

Resumo

Neste trabalho são apresentados conceitos do sistema de propriedade intelectual e os benefícios que podem trazer para a projeção do País no cenário internacional, quando aliados aos atores que compõem a pós-graduação. São apresentados dados consolidados do País que denotam a situação da propriedade intelectual na universidade e na empresa, à luz dos desdobramentos proporcionados pela legislação vigente. Propostas de ações são apresentadas, bem como os impactos provenientes do ensinamento de propriedade intelectual na formação do pesquisador brasileiro.

Palavras-chave: Propriedade Intelectual. Inovação. Desenvolvimento Econômico. Ensino. Pesquisa. Pós-Graduação. 


\section{Abstract}

This paper presents the concepts of the Brazilian intellectual property system and its benefits to the international projection of the country when aligned with those involved in graduate study. Consolidated data from Brazil are presented that show the country's intellectual property situation in the academia and business, in light of developments provided by law. Actions are proposed and the impacts of intellectual property teaching in shaping the Brazilian researcher are presented.

Keywords: Intellectual Property. Innovation. Economic Development. Teaching. Research. Graduate Study.

\section{Resumen}

En este trabajo se presentan los conceptos del sistema de propiedad intelectual y los beneficios que pueden aportar a la proyección del país en la escena internacional, al aliarse a los actores que integran el posgrado. Se presentan datos consolidados del país que muestran la situación de la propiedad intelectual en la universidad y la empresa, a la luz de las consecuencias resultantes de la ley vigente. Se presentan propuestas de acciones, así como los impactos de la enseñanza de la propiedad intelectual en la formación del investigador brasileño.

Palabras clave: Propiedad Intelectual. Innovación. Desarrollo Económico. Enseñanza. Investigación. Posgrado.

\section{Propriedade intelectual}

Órgão vinculado ao Ministério do Desenvolvimento, Indústria e Comércio Exterior, responsável pelo aperfeiçoamento, pela disseminação e gestão do sistema brasileiro de concessão e garantia de direitos de propriedade intelectual para a indústria.
O crescente número de patentes registradas no Instituto Nacional da Propriedade Industrial ${ }^{1}$ (Inpi), no decorrer dos últimos anos, denota um aumento significativo da consciência da sociedade brasileira sobre a importância do sistema de propriedade intelectual para o País (CAMARGO, 2012). O emprego desse sistema, desde a concepção inicial de uma pesquisa ou de um projeto, é fundamental 
para resguardar conhecimentos, desde os mais simples até os que possuem um relevante potencial econômico e tecnológico para o País.

Dentro do contexto das relações internacionais, a propriedade intelectual pode contribuir para o fortalecimento da economia brasileira por meio do conceito de soft power, que é a capacidade de um país influenciar outros por meios ideológicos e não pelas suas dimensões continentais, pela população ou pelo PIB (hard power). De forma recente, o soft power do Brasil vem se firmando por meio da cultura carismática (música, sociabilidade, entre outros) e da forte estabilidade econômica, graças à qual o País vem contornando as crises econômicas internacionais (LUSTIG, 2010).

São em pilares socioeconômicos como esse que o País tem firmado suas bases dentro do cenário das relações internacionais. Além desses pilares, o reconhecimento da propriedade intelectual, que resulta da capacidade inventiva e do intelecto brasileiro, vem se projetando cada vez mais nos ambientes internacionais das empresas e academias. Nesse contexto, convém ressaltar que, anteriormente, a formação de nível superior do brasileiro limitava-se às universidades do País, com exceções individuais em instituições no exterior. Atualmente, com o programa Ciências sem Fronteiras, lançado pelo Governo Federal em 26 de julho de 2011, as representações do potencial nacional expandiram-se a centros de excelência antes intangíveis, mas que agora recebem com o respeito adequado o pesquisador brasileiro.

A propriedade intelectual pode se tornar estática e improdutiva. Mas sua dinâmica pode evoluir para o capital intelectual, que corresponde a processos, métodos de formação, entre outros, ou, em um segundo momento, transformar-se em contratos comerciais. Um exemplo simples dessa segunda vertente pode ser visualizado no desenvolvimento de uma tecnologia inovadora em centros de pesquisas nacional. Se essa tecnologia não for contemplada com o depósito de uma patente, o País corre o risco de que outra nação o faça e passe a receber os benefícios econômicos provenientes de contratos comerciais em que a originalidade brasileira não será considerada. 
Eis o ponto de convergência entre a propriedade intelectual e o softpowerdo Brasil. DeacordocomDrucker(1993), asociedadeencontrase evoluindo do capitalismo para a sociedade do conhecimento. E é nesse cenário internacional que a sociedade caminha em uma direção convergente, em que o conhecimento será o maior patrimônio de uma nação. Indicadores sociais e econômicos, de uma forma genérica, alertam de maneira contundente de que não haverá no futuro um lugar para as nações que não estabelecerem suas bases em sólidos alicerces do conhecimento. Aquelas que não o fizerem estarão fadadas a se tornarem dependentes das primeiras. Logo, indubitavelmente, todo o conhecimento produzido pelos pesquisadores nacionais, guardadas as proporções do estágio em que se enquadre, deve ser protegido adequadamente pelas leis internacionais que regulam a propriedade intelectual.

\section{Universidade e empresa}

É certo afirmar que nem todo o conhecimento reside na universidade. Os mecanismos da inovação nortearam diversas empresas a criarem incubadoras ou núcleos responsáveis pela pesquisa, pelo desenvolvimento e pela inovação, os quais vêm trazendo resultados vantajosos para as empresas brasileiras. A Petrobras é um exemplo de sucesso nesse contexto. Por meio de investimentos em incubadoras e parcerias com entidades de excelência, como o Instituto Alberto Luiz Coimbra de Pós-Graduação e Pesquisa de Engenharia da Universidade Federal do Rio de Janeiro (Coppe/UFRJ), ela vem desenvolvendo diversos projetos de Ciência, Tecnologia e Inovação (CT\&I) reconhecidos internacionalmente, nas áreas de exploração em águas profundas. Em outras palavras, devido a esse cenário, é nas empresas que a inovação tem gerado o capital intelectual.

Contudo, os atores desse teatro vêm mudando a cada dia. As parcerias entre empresas e universidades vêm aumentando significativamente por meio de negociações sobre produtos e serviços a partir das pesquisas desenvolvidas na academia. O problema surge na hora em que devem ser divididos os royalties e as patentes. Alguns 
empresários acreditam que devam se apossar de todo o patrimônio dos resultados alcançados pelo fato de terem financiado os trabalhos, e, dessa forma, cria-se o impasse entre a universidade e a empresa (BATISTA; JUSTUS, 2011).

Ainda no contexto acadêmico, nem sempre o posicionamento da universidade vem facilitando a cooperação com as empresas. De acordo com um relatório publicado pelo Centro de Gestão de Estudos Estratégicos (CGEE),

[...] as universidades não têm uma percepção adequada do significado das patentes e dos ganhos decorrentes dessas patentes. A geração do conhecimento é uma pré-condição para se requerer a patente, mas obter ganhos a partir da tecnologia desenvolvida envolve um conjunto de outros ativos dos quais as universidades não participam. Para lucrar com uma patente, as empresas devem investir em ativo fixo, preparar o produto inovador para lançamento no mercado, investir na geração de outros ativos intangíveis associados à inovação, etc... Enfim, o resultado comercial de um desenvolvimento não se restringe ao trabalho de pesquisa e as universidades não demonstram possuir essa percepção (2009, p. 78).

Em última análise, o binômio universidade-empresa vem estreitando os laços no decorrer dos anos. Todavia, ainda é evidente a carência de conhecimentos sobre a propriedade intelectual no âmbito acadêmico, especificamente no que tange à propriedade industrial2. Sem a inserção desse conhecimento na universidade, principalmente no âmbito da pós-graduação, o País estará mais distante de reduzir a defasagem existente entre a produção científica e a proteção da propriedade intelectual, por meio da geração de patentes.

Conforme o último relatório da UNESCO, atualmente o Brasil ocupa o $13^{\circ}$ lugar no ranking de produção de conhecimento, mas ainda é o $58^{\circ}$ na geração de patentes. Posicionamento que o projeta inadequadamente no cenário internacional, sendo a nação que possui a sexta maior economia do mundo (RONDANI, 2012). Por isso é de extrema importância que os conhecimentos sobre a propriedade intelectual não se limitem a alguns setores da universidade, mas, sim, à conscientização dos alunos de pós-graduação e pesquisadores

2 Ramo da propriedade intelectual que trata de produtos e serviços. 
universitários, que devem conhecer bem os mecanismos de inovação existentes para saber aplicá-los em contratos comerciais que beneficiem ambos os lados e, por consequência, o País.

\section{Patentes nas universidades}

A partir da sanção da Lei $n^{\circ}$ 10.973, de 02 de dezembro de 2004 (Lei da Inovação), que “dispõe sobre incentivos à inovação e à pesquisa científica e tecnológica no ambiente produtivo e dá outras providências", foram criados centros de apoio à inovação em diversas universidades. Por meio desses centros, os pesquisadores vêm conseguindo transformar suas propriedades intelectuais em capitais intelectuais, estreitando cada vez mais a distância que havia entre a academia e a indústria.

Um exemplo de sucesso da implantação de centros de apoio à inovação pode ser observado nos resultados alcançados pela Agência de Inovação da Unicamp (Inova), conforme destaca a reportagem do jornal Valor Econômico, de 26 de abril de 2012:

De 2004 a 2011, a Inova foi responsável pelo registro de 474 patentes no Instituto Nacional da Propriedade Intelectual (INPI) e 161 registros no exterior, além do licenciamento de 364 patentes, que geraram $\mathrm{R} \$$ 1,98 milhão em royalties... Em 2004, a Inova fechou 17 acordos; no ano passado foram 52 .

Com um total de 635 patentes depositadas, a Universidade de Campinas (Unicamp) tornou-se a universidade no País com o maior número de patentes depositadas, comparando-se com os dados do Sistema Nacional de Ciência, Tecnologia e Inovação do Centro de Gestão de Estudos Estratégicos (CGEE), do Ministério da Ciência Tecnologia e Inovação, coletados até maio de 2010.

Esse levantamento realizado pelo CGEE considerou somente universidades com conceito 7 e 6 na avaliação da Capes (2007), identificando 27 instituições e 2.504 patentes depositadas na data limite, em 2010. Após a Unicamp, destacaram-se a: 
- Universidade de São Paulo (USP), com 544 patentes;

- Universidade Federal de Viçosa (UFV), com 302 patentes; e

- Universidade Federal do Rio de Janeiro (UFRJ), com 238 patentes.

Com os dados do referido levantamento, pode ser destacada a situação dos depósitos de patentes de acordo com as regiões do País, conforme apresenta a figura 1.

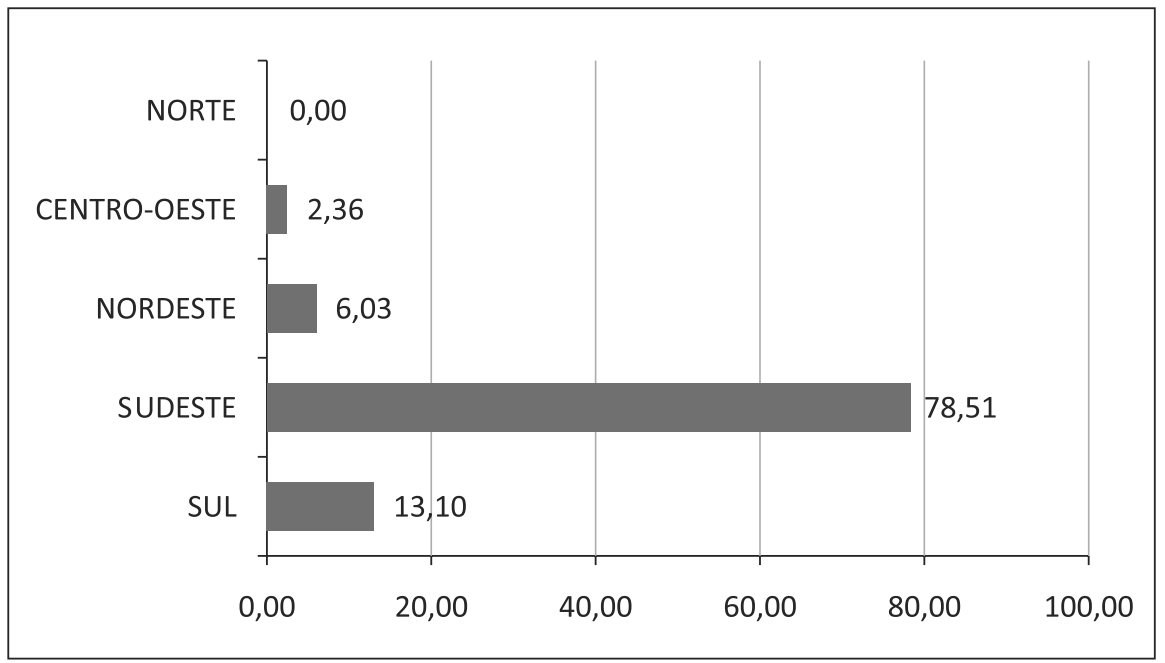

Fonte: Sistema Nacional de Ciência, Tecnologia e Inovação do Centro de Gestão de Estudos Estratégicos do Ministério da Ciência Tecnologia e Inovação. Acesso em: 30 abr. 2012. Dados coletados até maio de 2010.

Figura 1. Distribuição percentual dos depósitos de patentes realizados por universidades brasileiras por regiões do País

Essa distribuição insere a região Sudeste como grande depositante de patentes para o País, seja por meio da pós-graduação, como também pelas empresas, ou, ainda, pela parceria entre ambas. Nota-se que o número de empresas que possuem dispêndios realizados com atividades de CT\&l, só no estado de São Paulo, supera demasiadamente os valores existentes em outros estados (Tabela 1). Além disso, mais de 50\% dos parques tecnológicos e das incubadoras possuem sede na região Sudeste, o que facilita ainda mais o depósito de patentes. 
Tabela 1. Comparação de investimento entre os estados brasileiros quanto ao número de empresas que possuem dispêndios com atividades inovadoras

\begin{tabular}{|l|l|c|c|}
\hline \multicolumn{1}{|c|}{ Estado } & $\begin{array}{c}\text { Estado } \\
\text { (exemplos) }\end{array}$ & $\begin{array}{c}\mathbf{N}^{\circ} \text { de } \\
\text { empresas }\end{array}$ & $\begin{array}{c}\text { Valor total de dispêndios } \\
\text { realizados nas atividades } \\
\text { inovadoras (em R\$ 1.000,00) }\end{array}$ \\
\hline Sudeste & São Paulo & 10.063 & 21.933 .355 \\
\hline Sul & Santa Catarina & 2.710 & 1.502 .841 \\
\hline Nordeste & Bahia & 850 & 1.027 .608 \\
\hline Centro-Oeste & Goiás & 1.118 & 934.078 \\
\hline
\end{tabular}

Fonte: Pesquisa Industrial de Inovação Tecnológica em 2008 (Pintec), realizada pelo Instituto Brasileiro de Geografia e Estatística (IBGE).

Embora os cenários supracitados mostrem-se promissores, as pesquisas realizadas por órgãos respeitáveis como o CGEE ainda apontam um grau de inflexibilidade nas universidades nas relações de parceria com as empresas (CGEE, 2009). A exemplo, as regras estabelecidas por Núcleos de Inovação Tecnológica (NITs) de algumas universidades, pautadas na Lei da Inovação, por vezes dificultam acordos com o potencial de alavancar projetos inovadores que jazem nas teses e dissertações das bibliotecas universitárias (RONDANI, 2012).

Em outra análise, o modelo de inovação adotado atualmente pelas universidades também poderia sofrer alterações relevantes se fossem observados e empregados conceitos de propriedade intelectual. Voltando ao exemplo da Unicamp, embora a supracitada reportagem do jornal Valor Econômico tenha apontado o montante de $\mathrm{R} \$ 1,98$ milhão em royalties, este valor refere-se ao acumulado desde o ano de 2004 (INOVA UNICAMP, 2010). De acordo com Rondani, diretorexecutivo do Centro de Open Innovation Brasil, a Unicamp recebeu em royalties, em 2011 , apenas $0,001 \%$ de um orçamento anual de $\mathrm{R} \$ 2,2$ bilhões (RONDANI, 2012).

Isso não minimiza o trabalho desenvolvido pela agência Inova. Muito pelo contrário, denota que os esforços realizados pela referida agência, seus reconhecidos resultados e potenciais de crescimento 
são deveras promissores. No entanto, para que os percentuais em royalties recebidos pela universidade possam atingir cifras anuais mais relevantes, que impactem nos bens tangíveis e intangíveis da Unicamp, é necessário que a cultura organizacional do campus possa melhor entender e apoiar a Inova em seus trabalhos de sensibilização e na capacitação em propriedade intelectual.

Em outras universidades no País, o cenário não é diferente. Algumas dispõem, inclusive, de uma estrutura interna parceira do Instituto Nacional de Propriedade Industrial. No entanto, nem sempre os pesquisadores usufruem dos recursos de orientação e capacitação oferecidos.

A Universidade do Estado do Rio de Janeiro (Uerj) é um exemplo de academia em que o levantamento do CGEE apontou 12 patentes depositadas até maio de 2010. Comparando a quantidade de pesquisadores-doutores existentes em ambas as universidades, a Uerj possui cerca de 60\% a menos do total existente na Unicamp. No entanto, a mesma diferença não é proporcional conforme o depósito de patentes, cujo valor equivale a cerca de $2 \%$ do total depositado pela Unicamp. Em acertada decisão, a universidade firmou uma parceria com o Inpi em agosto de 2011 com a finalidade de sensibilizar e disseminar a propriedade intelectual no âmbito da universidade.

Exemplo similar ocorreu com a Universidade Federal de Pernambuco (UFPE). Com um total de 63 patentes depositadas até maio de 2010, juntamente com o Serviço de Apoio às Micro e Pequenas Empresas de Pernambuco (Sebrae-PE) e a Secretaria de Ciência e Tecnologia do Estado de Pernambuco, firmou parceria com o Inpi em outubro de 2011 com a mesma finalidade de sensibilizar e disseminar a propriedade intelectual no âmbito da universidade.

Esses dois casos denotam que as instituições vêm percebendo a necessidade de fomentar a cultura organizacional voltada para as atividades da propriedade intelectual. Todavia, no momento em que elas não fazem parte das atividades de pesquisa, ou das temáticas inseridas em sala de aula no campus das universidades, mais tardará para o pesquisador se interessar pelas ferramentas que podem 
potencializar suas respectivas soluções inovadoras em produtos ou serviços aplicáveis à indústria.

\section{Ampliação do conhecimento em propriedade intelectual}

Embora o cenário seja favorável em termos institucionais, o número de patentes depositadas poderia ser bem maior. Fora das salas dos centros de inovação das universidades, ainda há pesquisadores que desconhecem quase que totalmente os mecanismos que envolvem os sistemas de propriedade intelectual. Alguns se limitam a dizer que se preocupam com seus direitos autorais, mas não acompanham os processos do capital intelectual existentes na universidade. Assim, a consciência desse sistema, que se reflete na inovação tecnológica do País, por vezes aumenta aritmeticamente, quando deveria sofrer um crescimento exponencial.

No Brasil, seguindo a linha de vários outros países, como os Estados Unidos e a Alemanha, as experiências de ensino em propriedade intelectual limitavam-se a alguns cursos na área de Direito, tendo em vista que esse assunto somente era de interesse especial de advogados (AMORIM-BORHER et al., 2007). No entanto, para que seja incrementada a mentalidade sobre o assunto em outros setores produtivos das universidades, são necessárias ações que não são contempladas pela legislação vigente.

Como exemplo dessas ações, o Instituto Nacional da Propriedade Industrial vem envidando esforços relevantes no decorrer dos anos para tentar mudar a mentalidade e dar a devida importância ao assunto em todos os níveis da cadeia produtiva do País. Diversos simpósios, palestras e eventos têm sido realizados continuamente, além da criação, em 2006, de uma Academia de Propriedade Intelectual e Inovação, que permitiu a formação de diversos programas de curta duração, mestrado profissional, programas de ensino a distância e doutorado em Inovação e Propriedade Intelectual (aprovado pela Capes em 27 de setembro de 2012). 
Considerando as dimensões do País e a complexa rede de universidades inseridas no Sistema Nacional de Inovação, as ações do Inpi são relevantes e reconhecidas, mas não possuem estrutura suficiente para atender as dimensões continentais do País. A proposta deste artigo é evidenciar que a pós-graduação precisa começar a caminhar com os próprios pés nos conhecimentos afetos à propriedade intelectual, tendo como farol a legislação vigente e os exemplos contínuos do Inpi. Isso poderia ser realizado por meio de atividades de ensino inseridas na formação do pesquisador. Ressalta-se que a proposta não é reduzir a carga horária das disciplinas existentes ou sobrecarregar os alunos em fases críticas de sua formação, mas, sim, inserir pequenos módulos introdutórios aos conceitos de propriedade intelectual que permitissem despertar no aluno o entendimento adequado e a conscientização sobre o assunto.

Traçando, por exemplo, um paralelo com outras disciplinas ministradas nos cursos de mestrado, pode-se verificar que assuntos relacionados com metodologia de pesquisa estão presentes, ensinando aos novos pesquisadores a realizarem as suas atividades e publicarem seus resultados. Nesse sentido, por que também não ensiná-los a defender seus conhecimentos gerados em suas atividades inovadoras? Por que não ensiná-los a obter um retorno patrimonial de ativos tangíveis ou, se não para si, para suas instituições e para o próprio País? Com essa ferramenta bem sedimentada na formação, a cultura de patentes do futuro pesquisador poderá impactar significativamente na economia e no soft power do Brasil.

\section{Conclusão}

Investimentos em pesquisa geram novos desenvolvimentos. Novas patentes podem gerar grandes fontes de recursos para as universidades, fruto de suas licenças e seus royalties. Com esses recursos obtidos, as pesquisas podem ser mais aprofundadas, os laboratórios podem ser ampliados, a capacitação de mestres e doutores pode ser beneficiada e, principalmente, os processos de desenvolvimento de tecnologias autóctones podem ser consolidados. 
É todo um ciclo que se realimenta com os insumos da própria tecnologia desenvolvida e da inovação. No entanto, se a opção fosse buscar soluções prontas no exterior, o País estaria alimentando a cadeia de Ciência, Tecnologia e Inovação de outras nações, em detrimento à do Brasil. Felizmente, as políticas atuais vêm adotando cada vez mais a primeira linha, favorecendo o binômio formado pela indústria e pela academia nacionais.

Outro aspecto reside na cultura organizacional. É fato respeitável que nem todos aqueles que dividem os corredores e as salas da pós-graduação no País não entendem ou não dão o devido valor a temas afetos à propriedade intelectual. A questão pode não estar na pauta dos assuntos em lide; no entanto, ela passa a assumir uma dimensão significativa quando um pesquisador perde o crédito de anos de trabalho para outro que simplesmente patenteou a sua ideia. Isso é a evolução da sociedade capitalista para a sociedade do conhecimento, em que a gestão do que se produz intelectualmente pode ser a chave do sucesso (DRUCKER, 1993).

Finalmente, o Brasil é um país onde o número previsto de pesquisadores para se formar em 2012 atinge a grandeza de 41,3 mil mestres e 13,3 mil doutores (MEC, 2012). Suas políticas nacionais vigentes são favoráveis à inovação e podem ser beneficiadas pela propriedade intelectual. Considerando de forma genérica esses dois indicadores, perspectiva crescente de pesquisadores e políticas de apoio à inovação, aliados aos direitos provenientes da propriedade intelectual, pode-se notar o potencial brasileiro frente às demais nações que buscam uma posição de destaque no futuro dessa sociedade do conhecimento. Caberá ao País decidir, por meio do seu continuado esforço de desenvolvimento, em qual posição desejará estar no cenário internacional.

Recebido 30/04/2012 Aprovado 28/12/2012 


\section{Referências bibliográficas}

AMORIM-BORHER, M. B.; et. al. Ensino e Pesquisa em Propriedade Intelectual no Brasil. Revista Brasileira de Inovação, v. 6, n. 2, p. 281310, 2007.

BATISTA, H. G.; JUSTUS, P. O dilema da inovação: quando negociar é mais difícil que inventar. 0 Globo, Rio de Janeiro, 28 ago. 2011. p. 36.

CAMARGO, A. Rumos do INPI são discutidos no Dia da Propriedade Intelectual. Disponivel em: <http://www.inpi.gov.br/index.php?option =com_content $\&$ view=article $\&$ id=921:rumos-do-inpi-sao-discutidosno-dia-da-propriedade-intelectual\&catid=50:slideshow\&ltemid=146>. Acesso em: 30 abr. 2012.

CGEE - Centro de Gestão de Estudos Estratégicos. Os novos instrumentos de apoio à inovação: uma avaliação inicial. Brasília: CGEE, 2008. 101p.

DRUCKER, P. F. The Post-Capitalist Society. New York: HarperCollins Publishers, 1993.

IBGE - Instituto Brasileiro de Geografia e Estatística. Pesquisa Industrial de Inovação Tecnológica, 2008. Disponivel em: < http:/ / www. ibge.gov.br/home/estatistica/economia/industria/pintec/2008/ default.shtm>. Acesso em: 30 abr. 2012.

INOVA UNICAMP. Relatório de Atividades - Realizações da Agência de Inovação. Campinas: Agência de Inovação Inova Unicamp, 2010. 90p.

BRANDIMANTE, V. Legislação atual favorece registros por universidades. Valor Econômico, Rio de Janeiro, 26 abr. 2010. Caderno B, Empresas. Disponivel em: <http://www.valor.com.br/empresas/2633564/ legislacao-atual-favorece-registros-por-universidades>. Acesso em: 30 abr. 2012.

LUSTIG, R. Brazil extols 'soft power' skills. BBC News, Londres. Aba "Américas" do sítio da BBC na internet. 23 mar. 2010. Disponível em: 
<http://news.bbc.co.uk/2/hi/americas/8580560.stm>. Acesso em: 30 abr. 2012.

MEC - Ministério da Educação e Cultura. Número de mestres e doutores no mercado dobra em dez anos. Disponivel em: <http://portal.mec. gov.br/index.php?option=com_content\&view=article\&id=17534:nu mero-de-mestres-e-doutores-no-mercado-dobra-em-dez-anos\&catid=215\&ltemid=86>. Acesso em: 24 fev. 2012.

MCT - Ministério da Ciência e Tecnologia. Sistema Nacional de Ciência, Tecnologia e Inovação. Disponível em: <http://www.cgee.org.br/>. Acesso em: 30 abr. 2012.

RONDANI, B. Royalties são um entrave para inovação. 0 Estado de São Paulo, São Paulo, 03 set. 2012. Caderno de Economia. Disponível em: <http://www.estadao.com.br/noticias/impresso,royalties-saoentrave-para-inovacao-,925091,0.htm>. Acesso em: 31 out. 2012. 